\title{
ALTERATIONS IN THE IONIC COMPOSITION OF ISOTONIC SALINE SOLUTION INSTILLED INTO THE COLON ${ }^{1}$
}

\author{
By ANGELO D'AGOSTINO, WYLAND F. LEADBETTER, AND \\ WILLIAM B. SCHWARTZ ${ }^{2}$

\begin{abstract}
(From the Departments of Surgery [Urology] and Medicine of the New England Center Hospital, the Ziskind Research Laboratories, and Tufts College Medical School, Boston, Mass.)
\end{abstract}

(Submitted for publication July 2, 1952; accepted January 28, 1953)

Relatively little is known about the transport of electrolytes across the colonic mucosa, but it has generally been assumed that the colon plays no specific part in maintaining the body's electrolyte equilibrium (1). In 1921 Goldschmidt and Dayton $(2,3,4)$ reported that the passage of chloride in and out of the colon depends solely on the concentration of chloride in the luminal fluid. Some years later DeBeer, Johnston and Wilson (5) noted a high concentration of bicarbonate and a raised $\mathrm{pH}$ in a small amount of fluid obtained from an isolated colonic loop. Recent studies of the human colon have demonstrated a preferential absorption of chloride over sodium $(6,7)$.

To evaluate further the role of the colon in electrolyte and acid-base equilibrium a study has been made of the changes in the composition of isotonic sodium chloride solution instilled into the isolated colon of the dog. The data obtained indicate that concentration gradients for chloride, bicarbonate, sodium and potassium are maintained across the colonic mucosa.

\section{METHODS}

Fourteen experiments were done in six adult dogs whose colons had previously been isolated by a modification of the technique of Larson-Bargen (8). In this procedure the ileum is transected as close to the cecum as possible, the recto-sigmoid colon is transected as far down in the pelvis as possible, and a side-ileo-end colostomy is done. After the distal ileal stump has been turned in, the proximal colonic segment is exteriorized through a left flank stab wound. At no time was more than $3 \mathrm{~cm}$. of ileum left. These manipulations allowed a blind pouch to be made consisting of the proximal three-fourths of the colon, keeping most of the blood-supply and nervesupply intact. To avoid overdistention during subsequent experiments, the capacity of each loop was measured under

1 This investigation was aided in part by grants from the Leo Lehman Research Fund, the National Heart Institute of the National Institutes of Health, U. S. Public Health Service, and Lakeside Laboratories Inc.

2 Markle Scholar in the Medical Sciences. direct vision at operation and was found to be $150-200 \mathrm{cc}$. The function of the loop was studied beginning three weeks after the operation and over a period not exceeding 16 weeks. During this time the loops were irrigated three or four times a week with isotonic sodium chloride solution. Previous estimates of the viability of this type of preparation and its usefulness in studying colonic function have been made by Johnston (9), who found no perceptible change in the physiology or histology of the colon after as long as seven months. Peristalsis and absorption of glucose and sodium chloride solutions of various concentrations were unchanged during this period (9). In the present studies, punch biopsies from various parts of the pouch taken at intervals showed no histologic abnormalities; moreover, no diminution in capacity occurred. Autopsy of the four animals used in these experiments confirmed the complete isolation of the colonic pouches and did not reveal fistulae.

Experiments were performed by instilling 150 to 200 cc. of isotonic $155 \mathrm{mM}$. sodium chloride solution through an indwelling, double-ballooned, multi-eyed, Foley-type catheter. Complete closure of the colonic stoma was achieved by placing one balloon just inside the pouch and the other just outside. Specimens were collected in the initial shorter experiments at 15 to 30 minute intervals, but in the later experiments collections were made every one or two hours. The experiments were ended when no further fluid could be recovered. Fluid was withdrawn by unclamping the indwelling catheter and allowing a free flow. The final specimen was recovered by deflating both balloons and inserting the catheter to the full length of the pouch, to drain any fluid pocketed off by segmentation. All specimens were collected and centrifuged under oil. The clear supernatant was analyzed for carbon dioxide content, sodium, potassium and chloride and $\mathrm{pH}$ by methods described previously from this laboratory (10). In most experiments the $\mathrm{pH}$ of the colonic fluid and the serum concentrations of sodium, potassium, chloride and carbon dioxide were determined several times.

In addition to the above experiments, four acute studies were done on healthy dogs under Nembutal anesthesia by Goldschmidt's (2) method of isolating the colon.

\section{RESULTS}

Tables I and II show the changes in colonic fluid and plasma in two representative examples of 


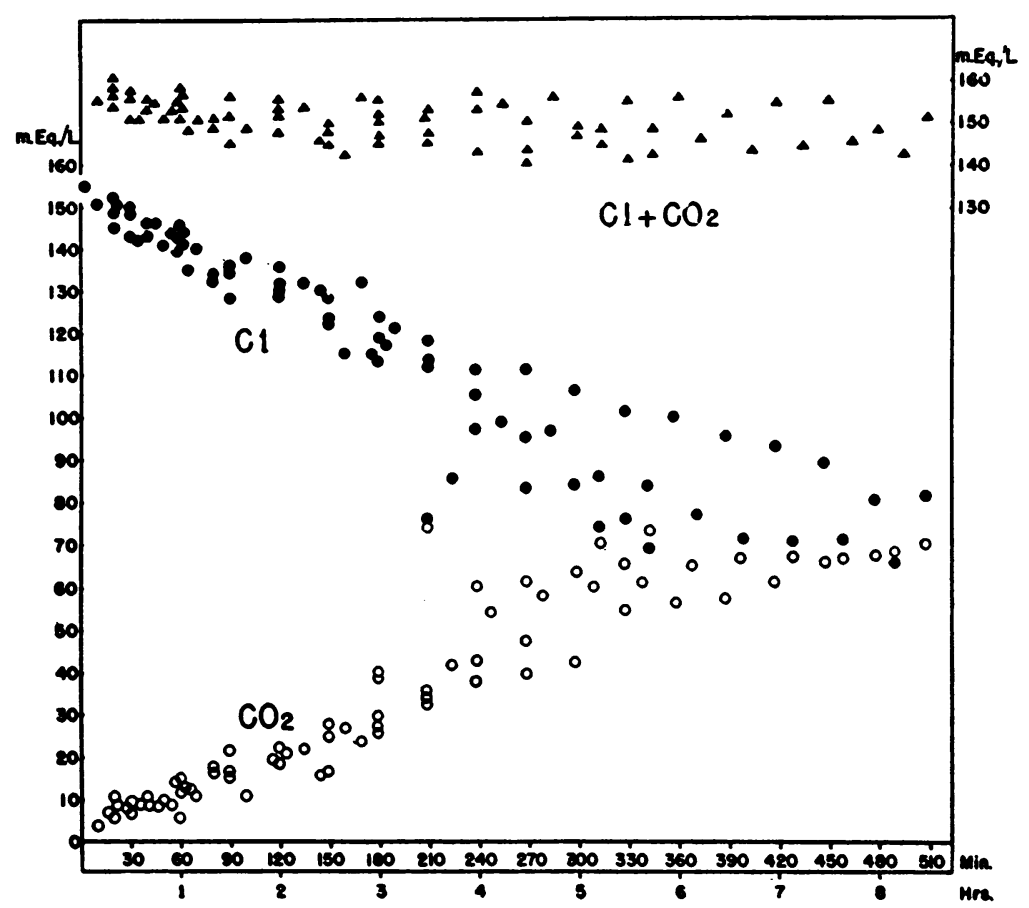

Fig. 1. Changes in Anion Composition of Isotonic Saline Solvtion InStilled into the Isolated Colon of the Dog (14 Experiments)

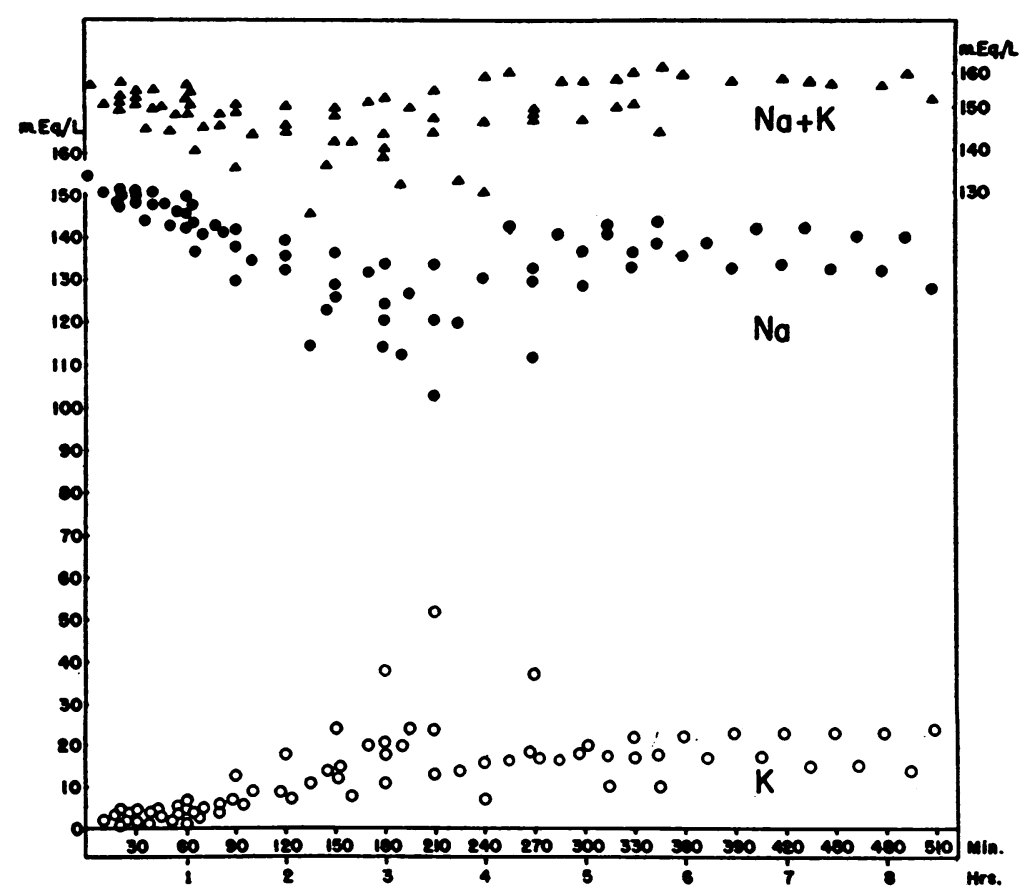

Fig. 2. Changes in Cation Composition of Isotonic Saline Solution InStilled into the Isolated Colon of the Dog (14 Experiments) 
TABLE I

Changes in the electrolyte composition of isotonic saline solution instilled into the colon of a dog

\begin{tabular}{|c|c|c|c|c|c|c|c|c|c|c|c|c|}
\hline \multirow[b]{2}{*}{$\begin{array}{l}\text { Spec. } \\
\text { No. }\end{array}$} & \multirow[b]{2}{*}{$\begin{array}{l}\text { Time, } \\
\text { mins. }\end{array}$} & \multicolumn{7}{|c|}{ Colonic fluid } & \multicolumn{4}{|c|}{ Serum } \\
\hline & & $\underset{m E_{q} / L}{\mathrm{Na}}$ & $\underset{m E q . / L}{\mathrm{~K}}$ & $\mathrm{Na}+\mathrm{K}$ & $\underset{m E Q_{.} / L}{\mathrm{Cl}}$ & $\underset{m E q . / L}{\mathrm{CO}_{2}}$ & $\mathrm{Cl}+\mathrm{CO}_{2}$ & $\begin{array}{l}\mathrm{Na}+\mathrm{K}+ \\
\mathrm{Cl}+\mathrm{CO}_{2}\end{array}$ & $\underset{m E q . / L}{\mathrm{Na}}$ & $\underset{m E q . / L}{\mathrm{~K}}$ & $\underset{m E_{Q} / L}{\mathrm{Cl}}$ & $\underset{m E q . / L}{\mathrm{CO}_{2}}$ \\
\hline $\begin{array}{l}1 \\
2 \\
3 \\
4 \\
5 \\
6 \\
7 \\
8 \\
9\end{array}$ & $\begin{array}{r}0 \\
60 \\
120 \\
180 \\
210 \\
240 \\
270 \\
300 \\
330\end{array}$ & $\begin{array}{l}155 \\
148 \\
140 \\
134 \\
135 \\
131 \\
130 \\
129 \\
133\end{array}$ & $\begin{array}{r}0 \\
1 \\
7 \\
11 \\
13 \\
16 \\
17 \\
18 \\
17\end{array}$ & $\begin{array}{l}155 \\
149 \\
147 \\
145 \\
148 \\
147 \\
147 \\
147 \\
150\end{array}$ & $\begin{array}{r}155 \\
147 \\
130 \\
119 \\
114 \\
106 \\
96 \\
85 \\
77\end{array}$ & $\begin{array}{r}0 \\
6 \\
19 \\
27 \\
33 \\
38 \\
48 \\
64 \\
66\end{array}$ & $\begin{array}{l}155 \\
153 \\
149 \\
146 \\
147 \\
144 \\
144 \\
149 \\
143\end{array}$ & $\begin{array}{l}310 \\
302 \\
296 \\
291 \\
295 \\
291 \\
291 \\
296 \\
293\end{array}$ & 146 & 5.0 & 114 & 19.5 \\
\hline
\end{tabular}

the 14 experiments. Figures 1 and 2 present the data for anions and cations respectively for the entire group. For purposes of discussion the carbon-dioxide content has been considered equivalent to bicarbonate concentration, since at the final $\mathrm{pH}$ range observed $(7.6$ to 8.0$)$ the calculated carbonic acid fraction (using a $\mathrm{pK}$ of 6.1) was no more than 1-3 mM. per L. In most experiments 40 to 60 per cent of the instilled fluid was recovered. Neither the rate of absorption nor the total amount of fluid absorbed affected the composition of the fluid recovered. In all experiments chloride concentration in the luminal fluid declined and the carbon dioxide content increased reciprocally. The carbon dioxide and chloride concentrations changed steadily for the first four to five hours and then appeared to level off at chloride concentrations of 70 to $90 \mathrm{mEq}$. per L and carbon dioxide contents of 50 to $70 \mathrm{mM}$. per L. The reciprocal relationship between chloride and bicarbonate tended to keep the sums of the final concentrations of these anions equal to, or only slightly less than, the original values. As shown in Tables I and II, the initial serumchloride concentration was usually moderately ele- vated and the carbon dioxide content moderately depressed. This was probably due to the mild chronic diarrhea present in all animals as the result of the ileosigmoidostomy. There were usually only slight changes in serum carbon dioxide content and chloride concentration during the experiments.

Figure 2 shows sodium and potassium concentrations in the luminal fluid. Sodium concentration fell to final levels ranging between approximately 110 and $140 \mathrm{mEq}$. per $\mathrm{L}$. The changes in sodium were accompanied by a rise in potassium concentration, usually to 15 to $20 \mathrm{mEq}$. per L. As a result, the sum of the concentrations of measured cations stayed constant or fell moderately. After three to four hours there was no further significant change. Table II shows an experiment in which the greatest fall in sodium and rise in potassium occurred, the sodium concentration declining to $103 \mathrm{mEq}$. per $\mathrm{L}$ while the potassium concentration rose to $52 \mathrm{mEq}$. per L. Serum sodium and potassium concentrations in all experiments in which they were measured were normal initially and did not change appreciably.

Total osmoles, as calculated from the sum of

TABLE II

Changes in the electrolyte composition of isotonic saline solution instilled into the colon of a dog

\begin{tabular}{|c|c|c|c|c|c|c|c|c|c|c|c|c|}
\hline \multirow[b]{2}{*}{$\begin{array}{l}\text { Spec. } \\
\text { No. }\end{array}$} & \multirow[b]{2}{*}{$\begin{array}{l}\text { Time, } \\
\text { mins. }\end{array}$} & \multicolumn{7}{|c|}{ Colonic fluid } & \multicolumn{4}{|c|}{ Serum } \\
\hline & & $\underset{m E_{Q} / L}{\mathrm{Na}}$ & $\underset{m E q . / L}{\mathrm{~K}}$ & $\mathrm{Na}+\mathrm{K}$ & $\underset{m E q . / L}{\mathrm{Cl}}$ & $\underset{m E_{Q} \cdot / L}{\mathrm{CO}_{2}}$ & $\mathrm{Cl}+\mathrm{CO}_{2}$ & $\begin{array}{l}\mathrm{Na}+\mathrm{K}+ \\
\mathrm{Cl}+\mathrm{CO}_{2}\end{array}$ & $\underset{m E q . / L}{\mathrm{Na}}$ & $\underset{m E_{Q} / L}{\mathrm{~K}}$ & $\underset{m E_{q} / L}{\mathrm{Cl}}$ & $\underset{m E q . / L}{\mathrm{CO}_{2}}$ \\
\hline $\begin{array}{l}1 \\
2 \\
3 \\
4 \\
5 \\
6 \\
7 \\
8\end{array}$ & $\begin{array}{r}0 \\
30 \\
60 \\
90 \\
120 \\
150 \\
180 \\
210\end{array}$ & $\begin{array}{l}155 \\
151 \\
143 \\
138 \\
133 \\
126 \\
115 \\
103\end{array}$ & $\begin{array}{r}0 \\
3 \\
7 \\
13 \\
18 \\
24 \\
38 \\
52\end{array}$ & $\begin{array}{l}155 \\
154 \\
150 \\
151 \\
151 \\
150 \\
153 \\
155\end{array}$ & $\begin{array}{r}155 \\
150 \\
142 \\
136 \\
132 \\
123 \\
116 \\
77\end{array}$ & $\begin{array}{r}0 \\
8 \\
13 \\
22 \\
22 \\
28 \\
40 \\
75\end{array}$ & $\begin{array}{l}155 \\
158 \\
155 \\
158 \\
154 \\
151 \\
156 \\
152\end{array}$ & $\begin{array}{l}310 \\
312 \\
305 \\
309 \\
305 \\
301 \\
309 \\
307\end{array}$ & 145 & 5.2 & 108 & 19.5 \\
\hline
\end{tabular}


sodium, potassium, chloride and carbon dioxide content, occasionally remained unchanged but usually fell slightly.

In the four acute experiments done under Nembutal anesthesia, the changes in carbon dioxide content, chloride, sodium and potassium were similar to those observed in the chronic experiments. In four additional experiments carried out following marked reductions in the bacterial flora as the result of antibiotics given orally and by infusions in the loop, the changes were also comparable to those shown in Figures 1 and 2.

\section{DISCUSSION}

The data demonstrate that concentration gradients for chloride and bicarbonate are maintained across the colonic mucosa. These cannot be accounted for by a simple Donnan equilibrium expression but could be explained by postulating that the colonic mucosa secretes bicarbonate into the lumen or actively absorbs chloride into the plasma in an exchange for bicarbonate. If, on the other hand, there were any source of bicarbonate ion inside the colon, the findings might also be explained without invoking an active transport of either bicarbonate or chloride. Splitting of urea by bacteria in the large bowel produces bicarbonate and ammonium and may serve as a continuing source of bicarbonate ions. The constant generation inside the colon of bicarbonate and its subsequent diffusion into the plasma could establish and maintain concentration differences of the observed magnitude. Although from the present data it is not possible to choose between the alternatives of active transport and rapid generation of bicarbonate as the mechanism primarily responsible for the observed changes in anion composition, there are several facts which suggest that ion secretion may be the fundamental factor. Firstly, although the experiments were carried out in many animals the rates of change in the bicarbonate and chloride concentrations and the final levels were remarkably constant. In addition, marked reduction in, and alteration of, the bacterial flora after antibiotic administration did not alter the pattern of response significantly. The fact that there was usually little or no depression of the sum of the concentrations of sodium and potassium implies that there was no large accumulation of the ammonium ion. This hypothesis has been confirmed by analyses for ammonium in several experiments (11) and indicates either that ammonium was reabsorbed at a far more rapid rate than bicarbonate produced simultaneously or that urea splitting could not account for the elevated bicarbonate concentrations. Definitive evidence for active transport would require sterilization of the colonic loop, a condition which has not been achieved in these studies.

If the colons in dog and man behave similarly, the present observations would seem to account for, at least partly, the development of hyperchloremic acidosis after ureteroenterostomy (1214). Regardless of whether the changes in the composition of the fluid in the lumen are due to a loss of bicarbonate from the plasma in exchange for chloride or to the absorption of chloride and ammonium from the lumen, the effect on the acidbase equilibrium would be the same. The clinical finding that urinary stasis in the colon increases the severity of the acidosis in patients with ureteroenterostomy $(12,13)$ is consistent with the present observations of progressive change in the instilled solution during the first four to five hours of study. The degree of acid-base disturbance which ultimately results probably depends in part on the integrity of renal function.

The data also indicate that in many instances concentration gradients for sodium and potassium, not explainable by a simple Donnan equilibrium expression, are maintained across the colonic mucosa. This is probably due either to secretion of potassium or to active absorption of sodium. The accumulation of ammonium might explain in part the depression of sodium concentration when the latter was unaccompanied by a reciprocal rise in potassium but would not explain the increased potassium concentration. The relationship of the elevated potassium levels in the colonic fluid to the high potassium concentrations in diarrheal stools requires further study.

A consideration of total osmoles as calculated from sodium, potassium, chloride and carbon dioxide content would indicate that the osmotic pressure of the original solution stays approximately the same or drops slightly. It has been shown by Diena (15) and Goldschmidt and Dayton (4) by measurement of freezing point depression that colonic contents are in osmotic equilibrium with blood. It would appear likely, therefore, that the 
apparent reductions in osmolarity calculated from some of the present data are due to the accumulation in the colonic fluid of unmeasured solutes.

\section{SUMMARY}

Following instillation of isotonic sodium chloride solution into the isolated colon of the dog, gradients are established across the colonic mucosa characterized by a higher concentration of bicarbonate and lower concentration of chloride in the colon than in the plasma. The sum of the concentrations of these anions in the colonic fluid remains essentially unchanged. The development of this equilibrium probably plays a part in the genesis of hyperchloremic acidosis after ureteroenterostomy. In most instances, concentration gradients across the colonic wall are also established for sodium and potassium.

\section{ACKNOWLEDGMENT}

The authors wish to express their appreciation to $\mathrm{Mr}$. Joseph Greaney for his valuable technical assistance.

\section{REFERENCES}

1. Welch, C. S., Wakefield, E. G., and Adams, M., Function of the large intestine of man in absorption and excretion. Study of a subject with an ileostomy stoma and an isolated colon. Arch. Int. Med., 1936, 58, 1095.

2. Goldschmidt, S., and Dayton, A. B., Studies in the mechanism of absorption from the intestine. I. The colon. A contribution to the one-sided permeability of the intestinal wall to chlorides. Am. J. Physiol., 1919, 48, 419.

3. Goldschmidt, S., and Dayton, A. B., Studies in the mechanism of absorption from the intestine. II.
The colon. On the passage of fluid in two directions through the intestinal wall. Am. J. Physiol., 1919, 48, 433.

4. Goldschmidt, S., and Dayton, A. B., Studies in the mechanism of absorption from the intestine. III. The colon. The osmotic pressure equilibrium between the intestinal contents and the blood. Am. J. Physiol., 1919, 48, 440.

5. DeBeer, E. J., Johnston, C. G., and Wilson, D. W., The composition of intestinal secretions. J. Biol. Chem., 1935, 108, 113.

6. Parsons, F. M., Powell, F. J. N., and Pyrah, L. N., Chemical imbalance following ureterocolic anastomosis. Lancet, 1952, 2, 599.

7. Annis, D., and Alexander, M. K., Differential absorption of electrolytes from the large bowel in relation to ureterosigmoid anastomosis. Lancet, 1952, 2, 603.

8. Larson, L. M., and Bargen, J. A., Action of cathartics on isolated dog's colon. I. Secretory activity. Arch. Surg., 1933, 27, 1120.

9. Johnston, C. G., A method for making quantitative intestinal studies. Proc. Soc. Exper. Biol. \& Med., 1932, 30, 193.

10. Relman, A. S., and Schwartz, W. B., The effect of DOCA on electrolyte balance in normal man and its relation to sodium chloride intake. Yale $\mathrm{J}$. Biol. \& Med., 1952, 24, 540.

11. Schwartz, W. B., Leadbetter, W. F., and D'Agostino, A., Unpublished observations.

12. Ferris, D. O., and Odel, H. M., Electrolyte pattern of the blood after bilateral ureterosigmoidostomy. J. A. M. A., 1950, 142, 634.

13. Odel, H. M., Ferris, D. O., and Priestley, J. T., Further observations on the electrolyte pattern of the blood after bilateral ureterosigmoidostomy. J. Urol., 1951, 65, 1013.

14. Doroshow, H. S., Electrolyte imbalance following bilateral ureterosigmoidostomy. J. Urol., 1951, 65, 831.

15. Diena, G., Quoted by Goldschmidt and Dayton (4). 